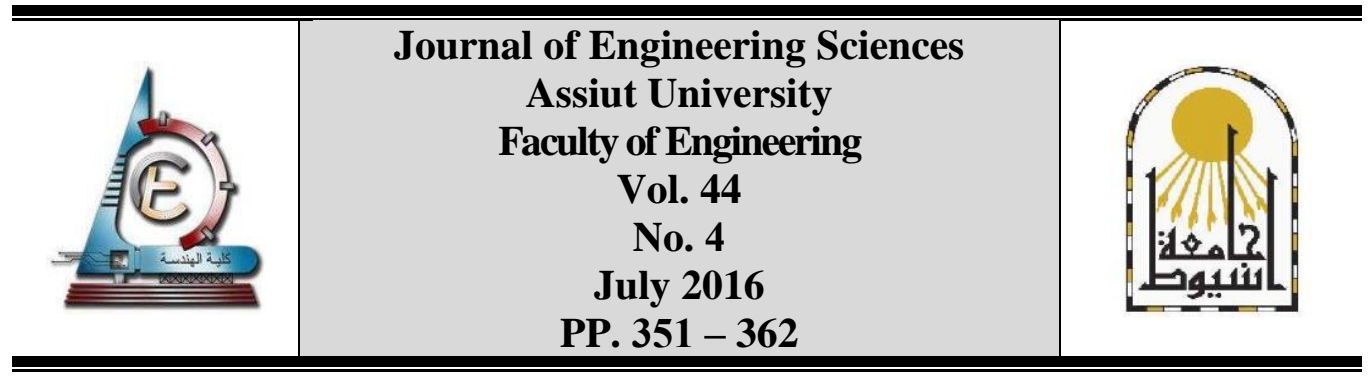

\title{
SIMPLIFICATION OF WATER SUPPLY SYSTEMS FOR PRODUCING MORE OPTIMAL PUMP SCHEDULES IN LESS TIMES
}

\author{
Nashat A. Ali, Gamal Abozeid, Moustafa S. Darweesh and Mohamed Mamdouh *
}

Staff in Civil Eng Dept, Faculty of Engineering, Assuit Univ, 71516 Assuit.

Received 23 March 2016; Accepted 25 June 2016

\begin{abstract}
Simplification of large water supply networks is used for reducing computation times and for making it easier to manage, monitor and analyze. The effect of networks' simplification on raising the efficiency of pump optimization process is investigated. The key topic of this paper is to produce more optimal pump schedules by using simplified networks. In this research, twelve of demand allocation methods are used after the simplification process and the best one is selected. Then, the simplified network is used for finding a better pump schedule than that produced from the original one under the same conditions, by using Genetic Algorithm (GA) in WaterGEMS V8i software. The produced schedule from the simplified network is applied on the original network to check its performance. Two examples are studied. First, Scheduler Sample1 is reduced by $52 \%$ for pipes and $50 \%$ of nodes. The schedule produced from the simplified network, after applying it on the original network, gives a better solution than that produced from the original one by $9 \%$ in the energy cost along a week and by $12 \%$ in the time for optimization. Second, New El- Minia city network is simplified by removing $82 \%$ from its pipes and $77 \%$ of its nodes. The schedule produced from the simplified network saves the energy consumption along a week by $1.7 \%$ and the time for optimization by $74 \%$ after applying it on the original network.
\end{abstract}

Keywords: Pump optimization, pipes network, simplification, demand allocation.

\section{Introduction}

Modeling of a hydraulic system is a main issue, and it is not always convenient to model every component in the network. Skeletonization of the network to a simplified one reduces its complexity for calibration, operation and monitoring purposes. However, the level of skeletonization used depends on the intended use of the model (Lamoudi et al. [7]). Maschler \& Savic [8] specified two main ways to simplify a network model, which are simplification of network model components and black box simplification. Mohamed and Ahmed [9] used the first way in three levels to study the effect of network simplification on the chlorine distribution. They found that increasing network simplification could effectively increase the error in water quality modeling. Gad and Mohamed [4] simplified a network by using the first

\footnotetext{
* Corresponding author.

E- mail address: engmohanoty2013@yahoo.com
} 
way in three levels and the impact of network's simplification on water hammer phenomenon was investigated. They found that increasing of simplification degree gave inaccurate transient pressure results. Moser and Smith [11] simplified a network by using the second way. They combined a strategy of model falsification with network reduction techniques to obtain reliable and efficient diagnoses. They found that this methodology had a potential to detect leak regions; even with a small number of sensors. Preis et al. [13] used the second way to reduce a network by $93 \%$ of its pipes and $97 \%$ of its nodes. They used the simplified model with statistical data-driven algorithm and GA to estimate future water demands. The simplified model reduced the computation time by $89 \%$. Paluszczyszyn et al. [12] used the second way to present an online simplification algorithm, which can be used to manage abnormal situations, and structural changes to a network, e.g. isolation of part of a network that due to a pipe burst. This approach allowed preserving the hydraulic and energetic characteristics of the original water network. Skworcow et al. [15] used the previous approach for reducing the network, while maintaining the energy distribution in the simplified network. The simplified network was used for minimizing the energy cost and leakage, while achieving operational constraints. Georgescu and Georgescu [5] reduced a real network by using a numerical network model and data recorded. By using the Honey Bees Mating Optimization Algorithm (HBMOA), they could save about $32 \%$ of daily energy consumption.

Many researchers harnessed GA for finding optimal pump schedules. Moreira and Ramos [10] reduced the daily energy cost of a real network by $43.7 \%$, by using GA with a manual override approach. Behandish and Wu [2] used the Artificial Neural Network (ANN) with GA to reduce the daily energy cost of a real system by about 10-15\%. Amirabdollahian and Mokhtari [1] utilized fuzzy genetic algorithm with uncertain hydraulic constraints to determine siting and sizing of tanks and pumps. They concluded that this approach reduced the computational costs and improved the network performance. Puleo et al. [14] coupled linear programming with GA. The proposed hybrid optimization model dominated on the traditional metaheuristic algorithms in terms of rapid convergence and reliability. Blinco et al. [3] developed a GA model to solve multi objectives pumping operation problem. The objectives were reducing cost, energy and Green House Gas emissions (GHG). They developed an interface, which allows users to employ this approach to their networks.

According to the above literature, simplification of water pipes network has been utilized for various aspects related to water distribution systems. Despite the enormous computational power available in these days, the requirements of water distribution systems become more complex and complicated in terms of size, objectives, and constraints. So, there is an ongoing seek for techniques or algorithms that can rapidly identify feasible solutions.

This study aim to investigate the effect of water networks simplification on pump optimization process to find better solutions in fewer times under the same hydraulic conditions and GA characteristics.

\section{Theoretical considerations}

The pump scheduling problem is treated as a single objective optimization problem subjected to some constraints. The objective function is given as follows (Giacomello et al. [6]);

$$
\min \sum_{t=1}^{T} \sum_{p=1}^{\text {NPumps }} \frac{\gamma c_{p, t}}{\eta_{p}} Q_{p, t} H_{p, t} \Delta t
$$


Where $T=$ number of hydraulic time steps during the operating period; NPumps = number of active pumps in the pump station; $\gamma=$ specific weight of water; $C_{P, T}=\operatorname{cost}$ of electricity (in pecuniary units per $\mathrm{KWh}$ ) during time $\mathrm{t}$ at pump station $p ; \eta_{p}=$ overall efficiency of pump $p ; Q_{p, t}=$ discharge of pump $p$ during time $t ; H_{p, t}=$ acting head of pump $p$ during time $t$; and $\Delta t=$ hydraulic time step (typically $1 \mathrm{hr}$ ).

This objective is restricted by physical and operational constraints. Physical constraints describe the hydraulic behavior of the network (conservation of mass and energy), while operational constraints are identified by the utility throughout the network to meet its needs.

The conservation of mass at junctions is defined as follows;

$$
\sum_{j} Q_{i j, t}=q_{i, t}
$$

Where $Q_{i j, t}=$ discharge in pipe $i j$ at time $t$; and $q_{i, t}=$ demand at junction $i$ at time $t$. Mass balance in tanks can be illustrated with the following equation;

$$
\sum_{j} Q_{i j, t}-\frac{S_{i}}{\Delta t}\left(Y_{i, t}-Y_{i, t-\Delta t}\right)=0
$$

Where $S_{i}=$ cross-sectional area of tank i (assuming cylindrical tank); $Y_{i, t}=$ water elevation in tank at time $\mathrm{t} ; Y_{i, t-\Delta t}=$ water elevation at previous time step; and $Y_{i, 0}=$ The water elevation in tank $i$ at the beginning of the operating period. Both Eqs. (2) and (3) are written for every junction at each time $t$. The conservation of energy equation is introduced as follows;

$$
H_{i, t}-H_{j, t}=R_{i j}\left|Q_{i j, t}\right|^{n-1} Q_{i j, t}
$$

Where $H_{i, t}$ and $H_{j, t}=$ heads in starting and ending junctions of pipe $i j$ at time $t ; \boldsymbol{R}_{i j}=$ resistance coefficient for pipe $i j$; and $n=$ exponent of discharge term.

factor when water enters a centrifugal pump $p$ is defined as follows;

$$
H_{p, t}=A_{p} Q_{p, t}^{2}+B_{p} Q_{p, t}+C_{p}
$$

Where $A_{p}$ and $B_{p}=$ two resistance coefficients; and $C_{p}=$ shutoff head. Both Eqs. (4) and (5) are written for every pipe $i j$ and every pump $p$ at each time $t$.

The operational constraints usually contain restrictions on nodal pressures, tank levels, and boundary conditions. Firstly, pressure constraint which means that the pressure should be above some minimum required value, $H^{\text {req }}{ }_{i, t}$, for each hydraulic time step $t$ at each node;

$$
H_{i, t} \geq H_{i, t}^{\mathrm{req}}
$$

If necessary, a maximum value of nodal pressure could also be added. In addition, the minimum and maximum water levels at all tanks must be constrained for each hydraulic time step $t$; 


$$
\begin{aligned}
& Y_{i}^{\min } \leq Y_{i, t} \\
& Y_{i, t} \leq Y_{i}^{\max }
\end{aligned}
$$

Where $Y^{\text {min }}{ }_{i}$ and $Y^{\text {max }}{ }_{i}=$ minimum and maximum water levels in tank $i$. In addition to that, each tank has to be operated in a way to ensure that the water level inside tank $i$ at the end of the day, $Y_{i, T}$, is more than that at the beginning of that day, $Y_{i, 0}$. This leads to reassure that tank balance will be achieved in the following day. This constraint can be expressed as follows;

$$
Y_{i, T} \geq Y_{i, 0}
$$

The operational constraints also contained velocity limitations which are;

$$
\begin{aligned}
V_{\text {min }} & \leq V_{i j, t} \\
V_{i j, t} & \leq V^{\max }
\end{aligned}
$$

Where $V_{i j, t}=$ water velocity of pipe $i j$ at time $t, V^{\min }$ and $V^{\max }=$ minimum and maximum water velocities in the pipe.

Furthermore, it is possible to calculate the search space of the pump optimization problems. If you have $N_{p}$ of pumps, $N_{s}$ of pump speed settings and $H_{s}$ of hydraulic time steps in your duration time, the search space is $S=N_{s}^{\wedge}\left(N_{p} * H_{s}\right)$.

\section{Case study}

Two examples are given in this study to illustrate the benefit of the network simplification in the pump optimization process.

\section{1- Example 1: Scheduler Sample 1}

SchedulerSample1 is a municipal water distribution network available in WaterCAD User's Guide [16] as shown in Fig. 1. This network contains 554 pipes and 458 nodes with looped and branch system. There is one source of water feeding the network with fixed water level $=184 \mathrm{~m}$, and a circular elevated tank of $14 \mathrm{~m}$ diameter with a height of $27 \mathrm{~m}$ as shown in Fig. 1. The initial tank level is $17.37 \mathrm{~m}$ at the beginning of the simulation time (24 hours). The network has a pump station containing 5 pumps and the total average daily demand is $93 \mathrm{~L} / \mathrm{s}$. Elevations of the network nodes, average base demands for the different nodes and time demand pattern are considered. The distribution system composes of $95,432.00 \mathrm{~m}$ of different diameter pipelines. All of them are ductile iron, and the head loss in each pipe is computed using Hazen-Williams formula. In addition to that, Fig. 2 shows the day hours when pumps are turned off and turned on in this network.

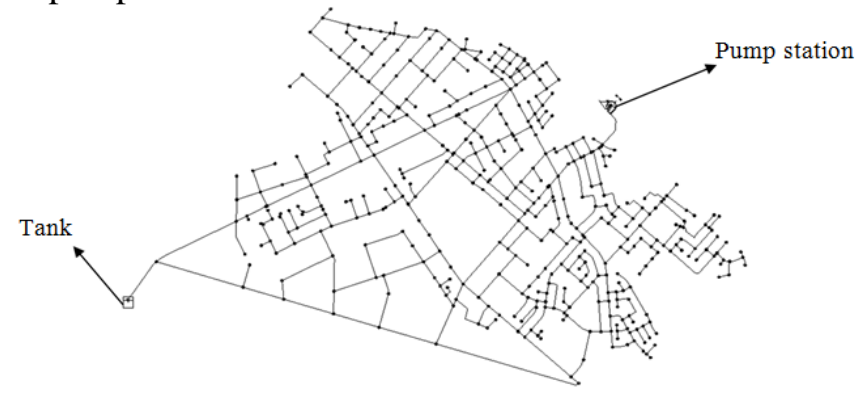

Fig. 1. Schedulersample1 network (the original network). 


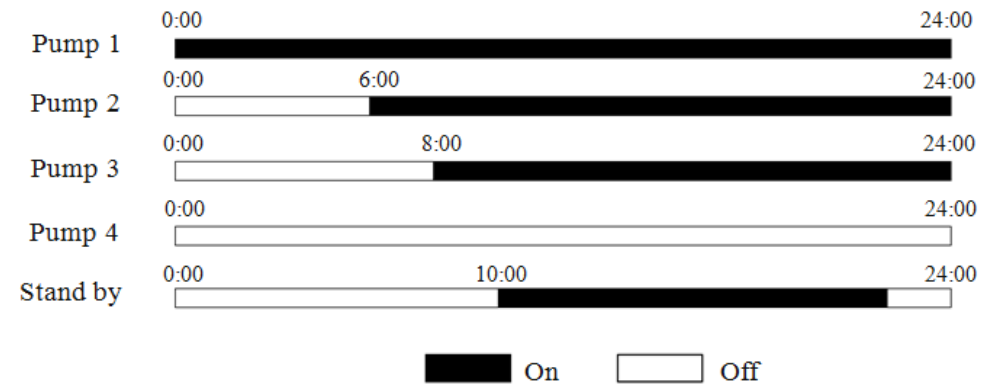

Fig. 2. The pump schedules of the Schedulersample1original network.

\section{2- Example 2: New El- Minia city network}

New El- Minia city is located about $250 \mathrm{~km}$ south of Cairo on the eastern bank of the River Nile, and has a drinking water distribution network as shown in Fig. 3. This network consists of 1348 pipes and 943 nodes, and there is one source of water feeding the network with water level $=150.96 \mathrm{~m}$. This network has a circular elevated tank of $19.4 \mathrm{~m}$ diameter with a height of $62 \mathrm{~m}$, and the total average daily demand is $170.7 \mathrm{~L} / \mathrm{s}$. Elevations of the network junctions, average base demands for the different junctions and time demand pattern are taken into consideration. The distribution system composes of $188 \mathrm{Km}$ of different diameter pipelines of Poly Vinyl Chloride (PVC), and the head loss in each pipe is computed using Hazen-Williams formula. Furthermore, Fig. 4 depicts that the pump station is working for 24 hours daily.

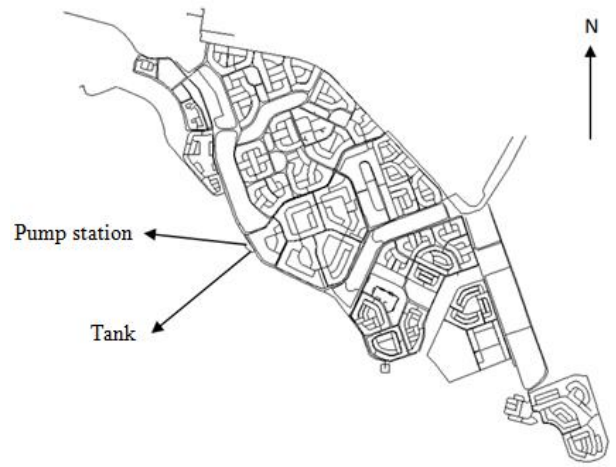

Fig. 3. New El- Minia city network (the original network).

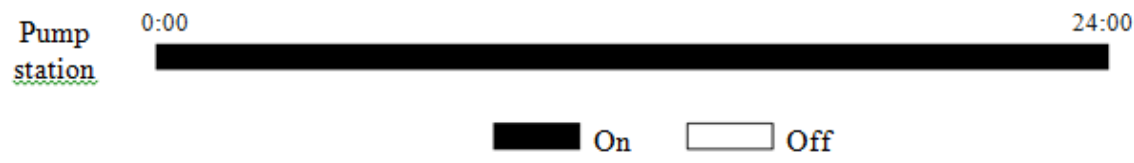

Fig. 4. The pump schedule of New El- Minia city network before optimization.

\section{Methodology}

First of all, simplification of network model components method, which includes deletion of trees, removal of small diameter pipes and trimming of short pipe segments including dead nodes (with no or little demand), is used intuitively to simplify water pipes network to make it easier for both analyzing and optimizing. Secondly, twelve of demand allocation methods (available in WaterGEMS V8i software) are used to redistribute the demands of the removed nodes to the simplified network, and the best method is selected 
to give the closest picture to the original network. For reducing the energy consumed by the pump station while achieving the physical and operational constraints, pump scheduling optimization is accomplished by using both the original network (without simplification) and the simplified one (with the best demand allocation method), with the same constraints and GA options in Darwin Scheduler (a tool in WaterGEMS V8i). Finally, a comparison between the performance of schedules, produced from the original and the simplified network has been done within the original network, to explore the effect of network simplification on facilitating the pump optimization process, in terms of percentage of saved energy and time taken for optimization.

\section{Results and discussions}

\subsection{Simplification process}

We adopt simplification of network model components procedure to reduce our networks. Deletion of trees, removal of small diameter pipes and trimming of short pipe segments including dead nodes (with no or little demand) are some techniques in this procedure. These techniques are used to skeletonize the studied networks. This kind of simplification does not contain any changes in pump stations or tanks. Schedulersample1 original network is reduced, from 554 pipes to 264 pipes (52\%) and from 458 nodes to 231 nodes (50\%), and shown in Fig. 5. New El- Minia city original network is reduced, from 1348 pipes to 243 pipes (82\%) and from 943 nodes to 221 nodes (77\%), and depicted in Fig. 6.

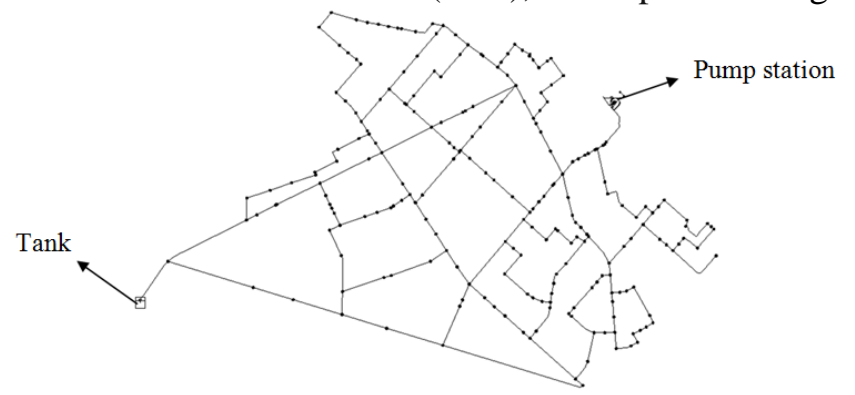

Fig. 5. Scheduler sample 1 network (the simplified network).

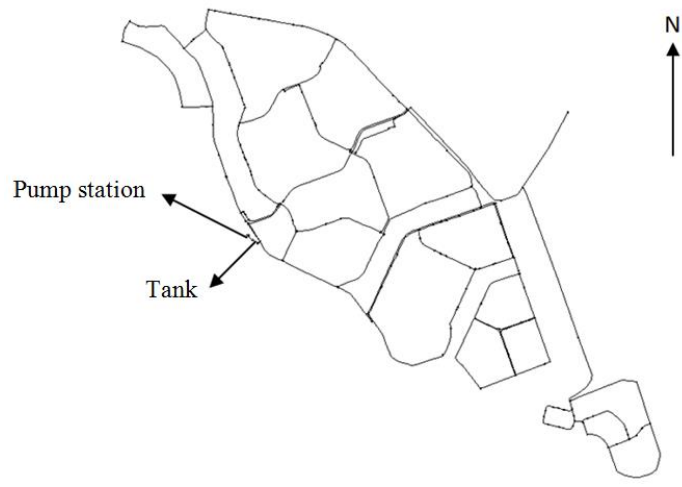

Fig. 6. New El- Minia city network (the simplified network).

Twelve of demand allocation methods, some of them are available in WaterCAD User's Guide [16], are used to reallocate the demands of the removed nodes to the simplified network. The best method is that produces flows in the pipes of the simplified network very close to flows in its corresponding pipes in the original network. These methods and their index values are listed in Table (1). 
JES, Assiut University, Faculty of Engineering, Vol. 44, No. 3, July 2016, pp. 351-362

Table 1.

The twelve demand allocation methods and their index values for the studied networks.

\begin{tabular}{|c|c|c|}
\hline Demand allocation method & $\begin{array}{c}\text { *Index value (L/s) for } \\
\text { Schedulersample1 } \\
\text { network }\end{array}$ & $\begin{array}{c}\text { *Index value (L/s) } \\
\text { for New El- Minia } \\
\text { city network }\end{array}$ \\
\hline Billing Meter Aggregation & 229.96 & 547.26 \\
\hline Nearest Node & 229.96 & 547.33 \\
\hline Nearest Pipe-Equal Distribution & 230.09 & 548.42 \\
\hline Nearest Pipe- Distance Weighted & 228.57 & 549.05 \\
\hline Nearest Pipe- Closest Node & 228.83 & 549.50 \\
\hline Nearest Pipe- Farthest Node & 234.38 & 547.62 \\
\hline Equal Flow Distribution & 433.87 & 542.94 \\
\hline Proportional Distribution by Area & 312.67 & 546.90 \\
\hline Unit Line & 255.39 & 537.50 \\
\hline Proportional Distribution by pipe's length & 284.09 & 549.68 \\
\hline $\begin{array}{c}\text { Proportional Distribution by Area based } \\
\text { on basic demand of original nodes }\end{array}$ & 278.73 & 539.93 \\
\hline $\begin{array}{c}\text { Equal Flow Distribution based on basic } \\
\text { demand of original nodes }\end{array}$ & 228.89 & 538.75 \\
\hline
\end{tabular}

*Index value is the sum of discrepancies between the flow of pipes, produced by the previous methods, on the simplified network and the flows of the same pipes in the original network.

From Table (1) the best methods for demand allocation are Nearest Pipe-Distance Weighted for Schedulersample1 network and Unit Line for New El- Minia city network. Then, we use the simplified network with the best demand allocation method in the optimization process.

\subsection{Pump optimization}

Darwin Scheduler, a tool in WaterGEMS V8i, is used to find optimal pump schedules under predefined constraints. This tool utilizes GA for its goal.

\subsubsection{Scheduler sample 1 network}

The objective in this network is reducing the energy cost along a week. The week has been choosen as a duration time to explore when the tank can achieve its balance (tank balance means that initial tank level = final tank level) in the week, despite violating the tank constraint on the first day. However, the demand and the energy tariff are assumed to be constant throughout the weekdays. This network is subjected to some constraints as tabulated in Table (2).

Table 2.

The constraints of Schedulersample1 network.

\begin{tabular}{|c|c|}
\hline Constraints & \multicolumn{1}{|c|}{ Values } \\
\hline Pressure & $\mathrm{P}_{\max }=140 \mathrm{~m}$ of water and $\mathrm{P}_{\min }=14 \mathrm{~m}$ of water \\
\hline Velocity & \multicolumn{1}{c|}{$\mathrm{V}_{\max }=6.1 \mathrm{~m} / \mathrm{s}$} \\
\hline Number of pump switches (on / off) daily & $\begin{array}{l}\text { Mnitial tank level = Final tank level on any day } \\
\text { during the week }\end{array}$ \\
\hline Tank & \\
\hline
\end{tabular}

By using the simplified network of Schedulersample1 and under the aforementioned constraints, the schedules shown in Fig. 7 are produced. The optimization process took 23 min. 


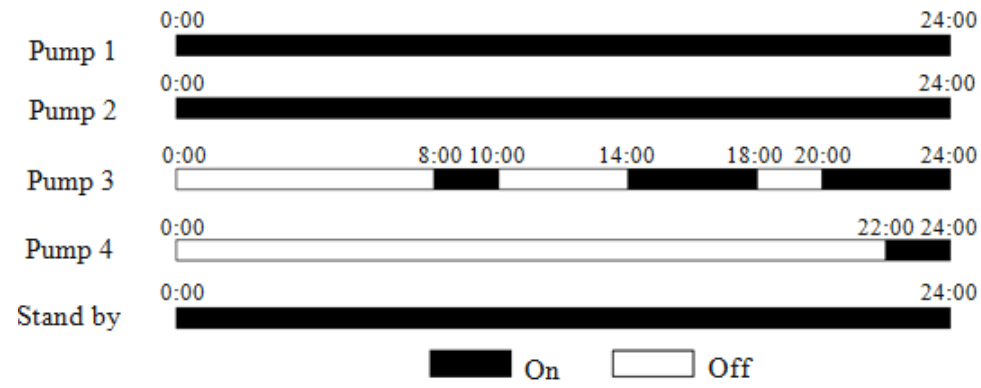

Fig. 7. The pump schedules produced from the Schedulersample1simplified network.

The optimization process is repeated with the original network of Schedulersample1 under the same constraints and the same GA options. The produced schedules are presented in Fig. 8. It is observed that the optimization process was achieved in $26 \mathrm{~min}$ with an increase of $11.5 \%$ compared to the simplified network.

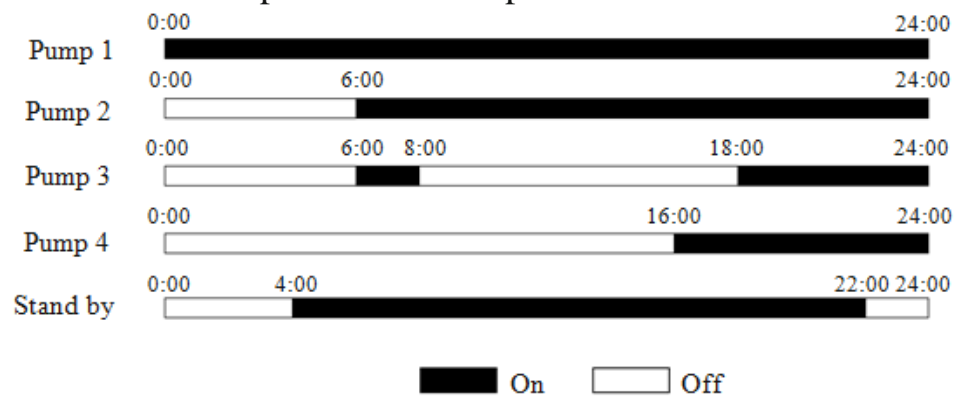

Fig. 8. The produced optimized schedules from the Schedulersampleloriginal network.

In Table (3), a comparison between the previous schedules (Figs. 5, 6 and 7) are made by applying them to the original network with full tank level on the first day of the week.

Table 3.

The performance of the previous schedules along a week.

\begin{tabular}{|c|c|c|c|c|}
\hline Schedules & $\begin{array}{c}\text { Energy cost } \\
(\$ / \text { week })\end{array}$ & $\begin{array}{c}\text { Pressure } \\
\text { constraint }\end{array}$ & $\begin{array}{c}\text { Velocity } \\
\text { constraint }\end{array}$ & Tank constraint \\
\hline Figure 7 & 1088 & $\begin{array}{c}\text { No } \\
\text { violation }\end{array}$ & $\begin{array}{c}\text { No } \\
\text { violation }\end{array}$ & $\begin{array}{c}\text { Tank balance is achieved on the } \\
\text { second day with } 15.28 \mathrm{~m}\end{array}$ \\
\hline Figure 8 & 1190 & $\begin{array}{c}\text { No } \\
\text { violation }\end{array}$ & $\begin{array}{c}\text { No } \\
\text { violation }\end{array}$ & $\begin{array}{c}\text { Tank balance is achieved on the first } \\
\text { day with } 17.37 \mathrm{~m}\end{array}$ \\
\hline Figure 2 & 1231 & $\begin{array}{c}\text { No } \\
\text { violation }\end{array}$ & $\begin{array}{c}\text { No } \\
\text { violation }\end{array}$ & $\begin{array}{c}\text { Tank balance is achieved on the } \\
\text { third day with } 12.51 \mathrm{~m}\end{array}$ \\
\hline
\end{tabular}

From Table (3), it is obvious that the energy cost of the schedules produced from the simplified network in Fig. 7 is less than the energy cost of the schedules produced from the original network in Fig. 8 by $9 \%$. In addition, the time taken to produce the schedules in Fig. 7 is less than the elapsed time to create the schedules in Fig. 6 by $11.5 \%$. On the other hand, pump 3 in the schedules produced from the simplified network in Fig. 7 has six switches per day which violate the number of pump switches constraint.

\subsubsection{New El-Minia city network}

Reducing the energy consumption is the objective in this network while achieving the constraint as listed in Table (4). 
JES, Assiut University, Faculty of Engineering, Vol. 44, No. 3, July 2016, pp. 351-362

\section{Table 4.}

The constraints of New El- Minia city network.

\begin{tabular}{|c|c|}
\hline Constraints & Values \\
\hline Pressure & $\mathrm{P}_{\min }=30 \mathrm{~m}$ of water \\
\hline Velocity & $\mathrm{V}_{\max }=2 \mathrm{~m} / \mathrm{s}$ \\
\hline $\begin{array}{c}\text { Number of pump switches } \\
\text { (on / off) daily }\end{array}$ & Max number of switches $=4$ \\
\hline Tank & $\begin{array}{c}\text { Initial tank level }=\text { Final tank level on any day } \\
\text { during the week }\end{array}$ \\
\hline
\end{tabular}

The optimization of the simplified network of New El- Minia City with the constraint presented in Table (4) produces the schedule as shown in Fig. 9 in 17 min. However, the optimization process under the same constraints and GA options when repeated with the original network of New El- Minia City, the schedule in Fig. 10 is produced in 66 min.

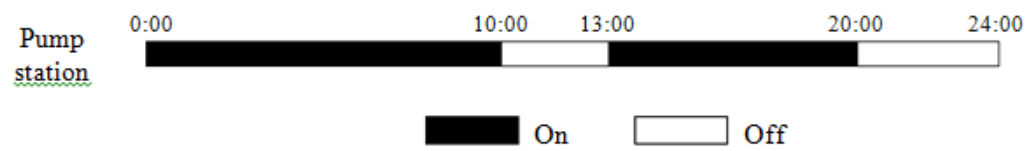

Fig. 9. The pump schedule of New El- Minia city simplified network.

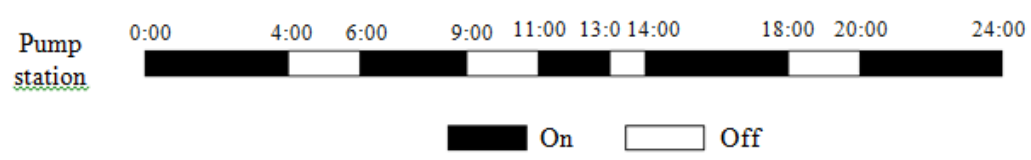

Fig. 10. The pump schedule of New El- Minia city original network.

The difference between the obtained schedules in Figs. 4, 9 and 10 is summarized in Table (5). The schedules are applied on the original network with $0.15 \mathrm{~m}$ as the initial tank level on the first day in the week.

Table 5.

The performance of New El- Minia City schedules of Figures 8,9 and 10 along a week.

\begin{tabular}{|c|c|c|c|c|}
\hline Schedules & $\begin{array}{c}\text { Energy } \\
\text { consumption } \\
\text { (kwh/week) }\end{array}$ & $\begin{array}{c}\text { Pressure } \\
\text { constraint }\end{array}$ & $\begin{array}{c}\text { Velocity } \\
\text { constraint }\end{array}$ & Tank constraint \\
\hline Figure 9 & 22526 & No violation & No violation & $\begin{array}{c}\text { Tank balance is achieved on the } \\
\text { second day with 1.58 m. }\end{array}$ \\
\hline Figure 10 & 22922 & No violation & No violation & $\begin{array}{c}\text { Tank balance is achieved on the } \\
\text { fourth day with 7.75 m. }\end{array}$ \\
\hline Figure 4 & 23071 & No violation & No violation & $\begin{array}{c}\text { Tank balance is achieved on the } \\
\text { second day with } 10.15 \mathrm{~m} .\end{array}$ \\
\hline
\end{tabular}

From Table (5), it is obvious that the energy consumption of the schedule produced from the simplified network in Fig. 9 is less than the energy consumption of the schedule produced from the original network in Fig. 10 by $1.8 \%$. In addition, the time taken to produce the schedule in Fig. 9 is less than the elapsed time to create the schedule in Fig. 10 by $74 \%$. Also, the schedule produced from the simplified network in Fig. 9 achieves the pump switches constraint unlike the schedule in Fig. 10 which violates this constraint by eight switches per day. On the other hand, Figure 4 shows the schedule of New El- Minia City network before optimization without any stops leading to a higher energy consumption compared to that of the optimized simplified network. 
Mohamed Mamdouh et al., Simplification of water supply systems for producing more optimal .......

Finally, Table (6) clarifies the effect of network simplification on facilitating the pump optimization process in terms of producing pump schedules with less energy consumption and take minimal time for optimizing. In terms of reducing the time taken for optimization, simplification of Schedulersample1 network by $51 \%$ in average has led to $11.5 \%$ save in time, and about $74 \%$ has been reduced after simplification of New El- Minia city network by $80 \%$. These percentages can be supported by the view that the software can deal with a simplified network easier than a complex one, especially when it comes to optimization problems which require a lot of iterations to find the optimum solution. So, the more the network is simplified, the less optimization time it will take. However, the remarkable difference, in decline of the optimization time between the two examples, is due to the difference in number of pumps in each example. By this I mean that, the first example has five pumps with size of search space equals $2^{\wedge}\left(5^{*} 24\right)$, but the second one has only one pump with $2^{\wedge}(1 * 24)$ search space size. Consequently, the bigger the search space you may have, the more time it will be taken for optimization. Owing to the fact that, New El- Minia city network has started its lifetime recently, with demand equals only $170.7 \mathrm{~L} / \mathrm{s}$ (around 145.41 $\mathrm{L} / \mathrm{s}$ go to the surrounding villages), the percentages of saved energy are not sensible enough, and subsequently the saved energy in the first case is 5 times higher than that in this network.

Table 6.

Comparison between saved energy and optimization time for the original and simplified networks of the two case studies.

\begin{tabular}{|c|c|c|c|c|c|}
\hline Example & Network & Simplification & $\begin{array}{l}\text { Optimized } \\
\text { pump } \\
\text { schedules }\end{array}$ & $\begin{array}{l}\text { Time for } \\
\text { optimizing } \\
\text { (min) }\end{array}$ & $\begin{array}{c}\text { Saved } \\
\text { percentage }\end{array}$ \\
\hline \multirow{3}{*}{$\begin{array}{c}\text { Schedulersample1 } \\
\text { network }\end{array}$} & Original & No & No & & \\
\hline & Original & No & Yes & 26 & $3.33 \%$ \\
\hline & Simplified & Yes & Yes & 23 & $11.62 \%$ \\
\hline \multirow{3}{*}{$\begin{array}{l}\text { New El- Minia city } \\
\text { network }\end{array}$} & Original & No & No & & \\
\hline & Original & No & Yes & 66 & $0.65 \%$ \\
\hline & Simplified & Yes & Yes & 17 & $2.36 \%$ \\
\hline
\end{tabular}

\section{Conclusions}

Simplification of network model components technique is used to skeletonize water distribution networks. Twelve of demand allocation methods are utilized to preserve that the overall system demand is kept unchanged in the reduced model. The best one is selected and used for finding optimal pump schedule. A comparison between this schedule and that produced from the original network after applying them on the original network is made.

Although, the studied simplification technique doesn't reduce the search space S. However, the time elapsed in the optimization process is reduced by $12 \%$ in example 1 and significantly by $74 \%$ in example 2 . Also, pump scheduling, created by using the simplified network, resulted in energy savings of $9 \%$ in example 1 and $1.7 \%$ in example 2, when compared to schedule, created by using the original network, with the same GA characteristics.

It is recommended that any suggested simplification technique used for pump optimization process should preserve both hydraulic and energy characteristics of the original network. Otherwise, the proposed schedules must be checked within the original network. 
JES, Assiut University, Faculty of Engineering, Vol. 44, No. 3, July 2016, pp. 351-362

\section{REFERENCES}

[1] Amirabdollahian, M. and Mokhtari, M., "Optimal design of pumped water distribution networks with storage under uncertain hydraulic constraints", J. of Water Resour. Manage., Vol. 29, Issue 8, pp. 2637-2653, (2015).

[2] Behandish, M. and $\mathrm{Wu}, \mathrm{Z}$. Y., "Concurrent pump scheduling and storage level optimization using meta-models and evolutionary algorithms", $12^{\text {th }}$ Int. Conf. on Computing and Control for the Water Industry, CCWI, Vol. 70, pp. 103-112, (2014).

[3] Blinco, L. J., Simpson, A. R., Lambert, M. F., Auricht, C. A., Hurr, N. E., Tiggemann, S. M. and Marchi, A. "Genetic algorithm optimization of operational costs and greenhouse gas emissions for water distribution systems", $16^{\text {th }}$ Water Distribution System Analysis Conf., WDSA- Urban Water Hydroinformatics and Strategic Planning, Vol. 89, pp. 509-516, (2014).

[4] Gad, A. A. M. and Mohamed, H. I., "Impact of pipes networks simplification on water hammer phenomenon", Sadhana j., Vol. 39, Issue 5, pp. 1227-1244, (2014).

[5] Georgescu, S. C. and Georgescu, A. M., "Application of HBMOA to pumping stations scheduling for a water distribution network with multiple tanks", $12^{\text {th }}$ Int. Conf. on Computing and Control for the Water Industry, CCWI, Vol. 70, pp. 715-723, (2014).

[6] Giacomello, C., Kapelan, Z. and Nicolini, M., "Fast hybrid optimization method for effective pump scheduling”, J. Water Resour. Plann. Manage, Vol. 139, Issue 2, pp. 175-183, (2013).

[7] Lamoudi, K. B., Bergerand, J. L. and Carrier, F., "Automated simplification of water networks models", Internship report - Master 2 CCI, (2013).

[8] Maschler, T. and Savic, D. A., "Simplification of water supply network models through linearization", Centre for Water Systems, Exeter University, Report No.99 (1), pp. 1-119, (1999).

[9] Mohamed, H. I. and Ahmed, S. S., "Effect of simplifying the water supply pipe networks on water quality simulation", Inter. Conf. for Water, Energy Environ., Sharijah, UAE, pp. 41-46, (2011).

[10] Moreira, D. F. and Ramos, H. M., "Energy cost optimization in a water supply system case study", J. of Energy. Vol. 2013, pp. 1-9, (2013).

[11] Moser, G. and Smith, I. F. C., "Detecting leak regions through model falsification", 20th Int. Workshop: Intelligent Computing in Engineering, Vienna, Austria, Jully 1-3, (2013).

[12] Paluszczyszyn, D., Skworcow, P. and Ulanicki, B., "Online simplification of water distribution network models for optimal scheduling", J. Hydroinformatics, (2013).

[13] Preis, A., Whittle, A. J., Asce, m., Ostfeld, A. and Perelman, L., "Efficient hydraulic state estimation technique using reduced models of urban water networks", J. Water Resour. Plann. Manage., Vol. 137, Issue 4, pp. 343-351, (2011).

[14] Puleo, V., Morley, M., Freni, G. and Savic, D. A., "A hybrid optimization method for real-time pump-scheduling", $11^{\text {th }}$ Int. Conf. on Hydroinformatics - HIC2014, New York, USA, (2014).

[15] Skworcow, P., Paluszczyszyn, D., Ulanicki, B., Rudek, R. and Belrain, T., "Optimization of pump and valve schedules in complex large-scale water distribution systems using GAMS modeling language", $12^{\text {th }}$ Int. Conf. on Computing and Control for the Water Industry, CCWI, Vol. 70, pp. 1566-1574, (2014).

[16] WaterCAD User's Guide: Water Distribution Modeling Software, Series 4, (2013). 


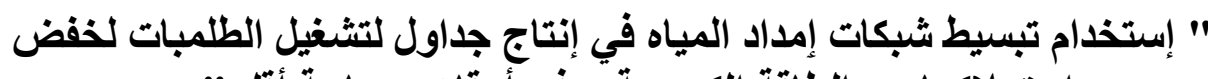

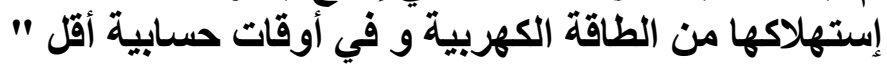

\section{الملخص العربى}

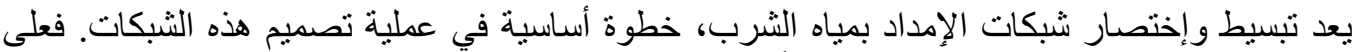

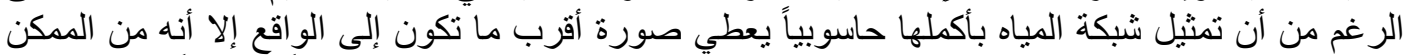

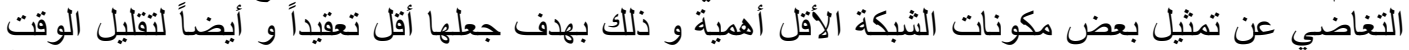

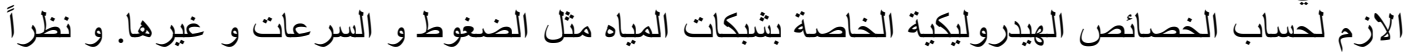

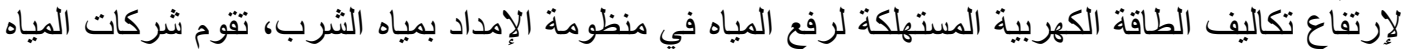

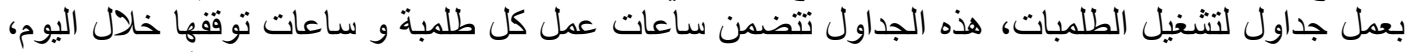

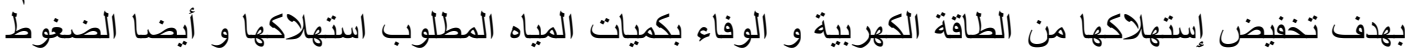

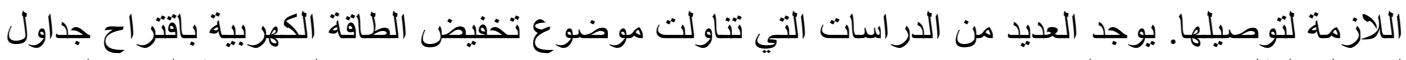

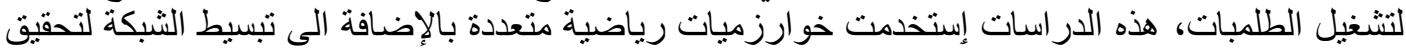
هذا الهذف و في أوقات حسابية أقل. و للالك كان الغرض من هذه الدراسة: 1. تبسيط شبكات المياه و إعادة توزيع إستهلاك المياه فيها بإنتانتدام اثني عشر طريقة مختلفة و إختيار

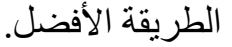
2. إستخدام الثبكة المبسطة ،بعد إعادة توزيع الإستهلاك بأفضل طريقة، في إنتاج جداول لتشغيل الطلمبات لخفض الطاقة الكهربية. 3. المقارنة بين جداول تشغيل الطلمبات التي تم إنتاجها بإستخدام الثبكة المبسطة و جداول تشغيل

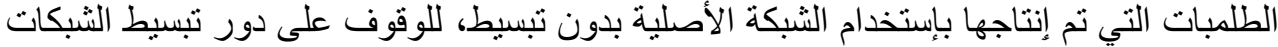

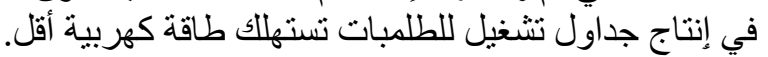

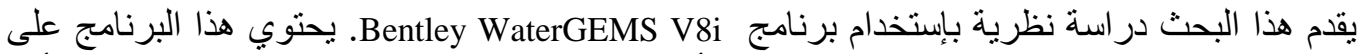

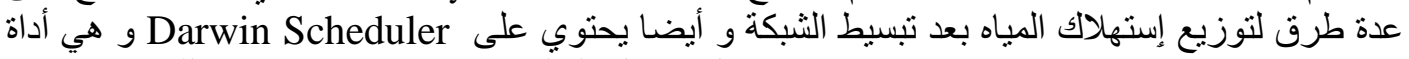
تستخدم Genetic Algorithm (GA) في إنتاج جداول تشغيل الطلمبات. تم إستخدام شبكنين للمياه، إحداهي اهما شبكة موجودة في أمثلة هذا البرنامج و آلأخرى شبكة حقيقية هي شبكة مياه الثرب بمدينة المنيا الجديدة، و ولئ

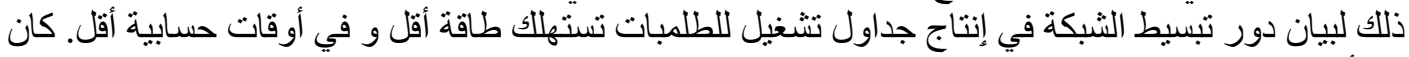

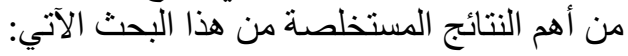

1. يمكن إنتاج جداول تشغيل للطلمبات تستهلك طاقة كهربية أقل و في أوقات أقل بإستخدام الثبكة

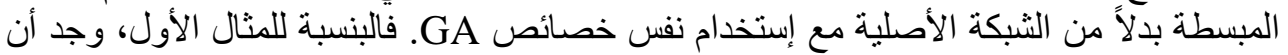

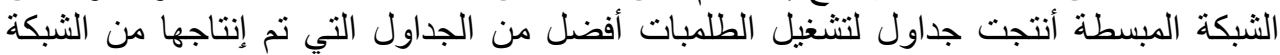

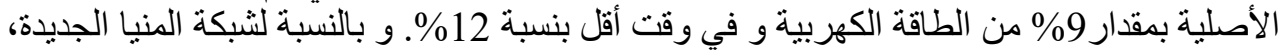

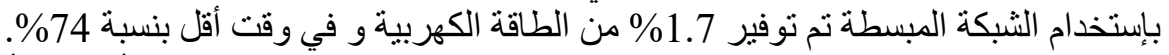
2. لابد من تطبيق الحلول التي تم إنتاجها من الشبكة المبسطة على الثلى الشبكة الأصلية لأن الثبة الثبكة

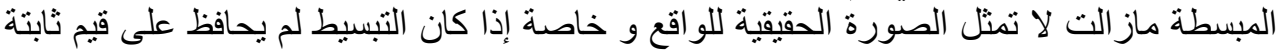

